Short Communication

\title{
AWARENESS ABOUT DIABETES AM ONG ADOLESCENTS OF MANGALORE, SOUTH INDIA
}

\author{
Rohith Holla', Sachin Prabhu', Sanjana Shetty', Shreya Deshpande', \\ Shwetha Balla K. ${ }^{1}$, Snigdha Hegde ${ }^{1}$, Soujanya B.S. ${ }^{1}$, Harsha Raj ${ }^{2}$ \& Rashmi Kundapur ${ }^{3}$ \\ ${ }^{1}$ M BBS Student (III Year), ${ }^{2}$ Medico Social Worker, ${ }^{3}$ Associate Professor, Department of Community M edicine, \\ K.S. Hegde M edical Academy, Nitte University, Deralakatte, M angalore - 575018 Karnataka, India. \\ Correspondence \\ Rashmi Kundapur \\ Associate Professor, Department of Community Medicine \\ K.S. Hegde M edical Academy, Nitte University, Deralakatte, Mangalore - 575 018, Karnataka, India. \\ Mobile : +919880496567 E-mail : dr.rashmi.kundapur@gmail.com
}

\begin{abstract}
:
Introduction: India continues to be the diabetic capital of the world. According to the WHO report, India today heads the world with 32 million patients and this number is projected to increase to 79.4 million by the year 2030. Diabetes has become a great economic challenge as it drains between $5-25 \%$ of family income of an average Indian.
\end{abstract}

Aims \& Objectives: To study the awareness of diabetes among the adolescents.

Materials and Method: Community based cross-sectional study. We collected data from 600 adolescents of age group 16-18years.A questionnaire consisting of questions that were based on the knowledge, awareness and practices regarding the risk factors of Diabetes were prepared. Students from 4 pre-university colleges in M angalore, Dakshina Kannada district, were selected as the study group

Results: $88.5 \%$ were aware of diabetes. According to $48.33 \%$ consumption of sweets only was a risk factor. $5.5 \%$ were aware that diabetes runs in families. $78.33 \%$ were aware that diabetes can affect any age group and $73 \%$ knew about the increasing rate of diabetes in India. $72.16 \%$ were sure that diabetes can be prevented and $25.5 \%$ said it was possible to completely cure $.46 \%$ were under a misconception that a vaccine is present for diabetes and only $57.83 \%$ were aware of that diabetes can cause complications.

Keywords: awareness of diabetes, awareness of complications, prevention of diabetes

\section{Introduction:}

India continues to be the diabetic capital of the world. According to the WHO report, India today heads the world with 32 million patients and this number is projected to increase to 79.4 million by the year 2030. Diabetes has become a great economic challenge as it drains between 5 $25 \%$ of family income of an average Indian. Recent survey indicates that diabetes now affects a staggering $10-15 \%$ of urban population and $5-8 \%$ of rural population. Several regions the country are still under developed and people \begin{tabular}{|c|}
\hline Access this article online \\
\hline Quick Response Code \\
\hline
\end{tabular}

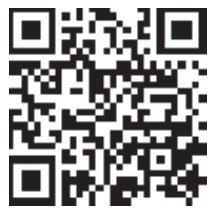
have several myths and beliefs regarding the disease. With increasing urbanization, many people are adopting unhealthy western lifestyles with reduced physical activity, sedentary lifestyle and excessive intake of calories ${ }^{[2]}$. This contributes to obesity which is a risk factor for development of diabetes ${ }^{[2]}$. We are seeing an increasing incidence of type 2 diabetes in the young as a result of obesity ${ }^{[2]}$. It is important to know about the awareness level of this condition as knowledge is a critical component of behavioral change ${ }^{[2]}$. Once awareness is created people are more likely to participate in prevention and control activities ${ }^{[2]}$. This study, therefore, set out to establish the awareness of diabetes among adolescents in M angalore.

\section{Aims \& Objectives:}

To study the awareness of diabetes among the adolescents.

\section{Materials and Method:}

Study technique: Community based cross-sectional study.

Study Sample: Taking into consideration $10 \%$ of the adolescents having knowledge about diabetes using 
formula, $n=4 p q / L^{2}$; where, $p=10 \%, q=1-p, L=3 \%$. With a confidence interval of $97 \% \&$ power of the study being $80 \%$, we get a sample of 400 .Considering few unfilled proformas, $20 \%$ excess sample was decided i.e. 480 adolescents. We collected data from 600 adolescents of age group 1618years.

\section{Methodology:}

A questionnaire consisting of questions that were based on the knowledge, awareness and practices regarding the risk factors of Diabetes were prepared. Students from 4 preuniversity colleges in Mangalore, Dakshina Kannada district, were selected as the study group. Only students willing to participate in the study were included. The questionnaire was to be filled anonymously. The questions being in English, an oral translation in the local language was given. Sufficient time was given to the students to complete the questionnaire. The data obtained were compiled manually and the results were tabulated.

\section{Results:}

$88.5 \%$ were aware of diabetes while $11.5 \%$ were not aware. According to $48.33 \%$ consumption of sweets only was a risk factor and $8.66 \%$ thought mental stress was a risk factor. $78.33 \%$ were aware that diabetes can affect any age group and $73 \%$ knew about the increasing rate of diabetes in india while $23 \%$ didn't know about it. $15.5 \%$ didn't know whether diabetes can be prevented while $72.16 \%$ were sure that it can be prevented. $24.66 \%$ didn't know whether there was a cure for diabetes while $25.5 \%$ said it was possible to completely cure and $49.83 \%$ said it was not possible to completely cure diabetes. $46 \%$ were under a misconception that a vaccine is present for diabetes. Only $57.83 \%$ were aware of that diabetes can cause complications.

Table 1: Awareness table

\begin{tabular}{|l|c|c|c|}
\hline & Yes & No & Don't know \\
\hline Awareness about diabetes & $88 \%$ & $11.5 \%$ & - \\
\hline Increase in rate of diabetes & $73 \%$ & $4 \%$ & $23 \%$ \\
\hline Complications of diabetes & $57.83 \%$ & $14 \%$ & $28.16 \%$ \\
\hline Prevention of diabetes & $72.16 \%$ & $12.33 \%$ & $15.5 \%$ \\
\hline Vaccine for diabetes & $46 \%$ & $23 \%$ & $31 \%$ \\
\hline Complete cure of diabetes & $25.5 \%$ & $49.83 \%$ & $24.66 \%$ \\
\hline Susceptibility to diabetes & $16.9 \%$ & $11.8 \%$ & - \\
\hline
\end{tabular}

Table 2: Risk factors

\begin{tabular}{|l|c|c|}
\hline & Yes & No \\
\hline Consuming sweets & $48.33 \%$ & $51.67 \%$ \\
\hline Smoking & $4.33 \%$ & $95.67 \%$ \\
\hline Family history & $5.5 \%$ & $94.5 \%$ \\
\hline Obesity & $5.33 \%$ & $94.67 \%$ \\
\hline M ental stress & $8.66 \%$ & $91.34 \%$ \\
\hline Alcohol & $4.66 \%$ & $95.34 \%$ \\
\hline Decreased physical activity & $7.33 \%$ & $92.67 \%$ \\
\hline
\end{tabular}

\section{Discussion:}

This is one of the rare studies done among pre -university students regarding the awareness of diabetes mellitus. Knowledge about knowing diabetes among 600 students was 531 i.e. $88 \%$ of students were aware about diabetes and study done in Kolar awareness was only $50.8 \%{ }^{[1]}$. In certain urban parts Pakistan knowledge of diabetes was $43 \%$ and the global score was $30 \%$. As our research was confined to educational institutes only awareness had been more. About $72 \%$ of students were of the opinion that incidence of diabetes is increasing these days. In Chennai ${ }^{[3]}$ it was found that $74.1 \%$ were of the opinion that diabetes was increasing. In our study $57.83 \%$ were aware of the complications to other organs, unlike our study other studies done in Chennai ${ }^{[3]}$ revealed that only $19 \%$ were aware of the complications. The $44 \%$ of students believed consumption of sweets alone was cause for diabetes, whereas $22.2 \%$ in Chennai ${ }^{[3]}$ believed that excessive sweets caused diabetes. This may be due to misinformation about diabetes from the family members and myth. In our study $18.33 \%$ of students were of the opinion that diabetes occurred at old age while in similar studies conducted in $\operatorname{Kolar}^{[1]} 30.17 \%$ were of the opinion that it occurs in old age. Since earlier study ${ }^{[1]}$ was a study of rural area majority were under the misconception that diabetes occurs in old age. $78.33 \%$ of the students in our study were of the opinion that it occurs in any age. Around $72.16 \%$ felt that it could be prevented whereas $91 \%$ of cases in studies done in Singapore felt that diabetes could be prevented. It is alarming to know that $46.16 \%$ believed that there is a vaccine for diabetes but earlier study done in Singapore showed that $76.2 \%$ were aware that there is no vaccine. The possibility of Singapore being a developed country the knowledge scored better in that area. High percentage of 
students in our study felt that there is a vaccine. This is because they are not fully aware about the chief aspects of diabetes and also misinformed. It is again important to see that $25.5 \%$ of the adolescents were of the opinion that diabetes is completely curable and $24.65 \%$ did not know. In studies done in Greece ${ }^{[4]} 77 \%$ knew that diabetes is incurable while $14 \%$ believed that it is an easily curable disease. This implicates the level of knowledge in developed countries is much higher than our country. This study revealed us that even though the adolescents knew about diabetes there was a lot of misconception about the disease and the risk factor knowledge which is very important wasalso poor.

\section{Acknowledgement:}

We thank the Head of the department, Dr. Uday Kiran Nalam and all the staff of Community medicine for their immense support during the study.

\section{Conclusion:}

Majority of the adolescents in the study knew about diabetes but had misconceptions on vaccine and treatment. There was also no proper knowledge about the risk factors associated with diabetes.

\section{References:}

1. C.M uninarayara,G.Balachandra,S.G $>$ Hiremath, Krishna Iyengar,N.S.Anil;Prevalance and awareness regarding diabetes mellitus in rural Tamaka,Kolar; International Journal on Diabetes in developing countries Volume 30 , issue 1

2. Knowledge, awareness and impact of diabetes among adolescents in Uyo, Nigeria, B C Unadike and S Chineye,African journal of diabetes medicine, May 2009

3. Deepa Mohan,Deepa Raj,CS Shanthirani,Manila Dutta,NC Unwin,A Kapor,V.Mohan;Awareness and Knowledge of Diabetes Mellitus in Chennai-The Chennai urban epidemiology study;JAPI,Volume 53,April 2005

4. Mariasomali, Christo, Georgios Mastorakos, Zadalla Mouslech; Diabetes awareness in the general population of Northern Greece 